\title{
Surgical outcomes of cervical spondylotic myelopathy: an analysis of a national, administrative, longitudinal database
}

\author{
*Anand Veeravagu, MD, lan D. Connolly, MS, Layton Lamsam, BS, Amy Li, BA, \\ Christian Swinney, BA, Tej D. Azad, BA, Atman Desai, MD, and John K. Ratliff, MD \\ Department of Neurosurgery, Stanford University School of Medicine, Palo Alto, California
}

OBJECTIVE The authors performed a population-based analysis of national trends, costs, and outcomes associated with cervical spondylotic myelopathy (CSM) in the United States. They assessed postoperative complications, resource utilization, and predictors of costs, in this surgically treated CSM population.

METHODS MarketScan data (2006-2010) were used to retrospectively analyze the complications and costs of different spine surgeries for CSM. The authors determined outcomes following anterior cervical discectomy and fusion (ACDF), posterior fusion, combined anterior/posterior fusion, and laminoplasty procedures.

RESULTS The authors identified 35,962 CSM patients, comprising 5154 elderly (age $\geq 65$ years) patients (mean 72.2 years, $54.9 \%$ male) and 30,808 nonelderly patients (mean 51.1 years, $49.3 \%$ male). They found an overall complication rate of $15.6 \%$ after ACDF, $29.2 \%$ after posterior fusion, $41.1 \%$ after combined anterior and posterior fusion, and $22.4 \%$ after laminoplasty. Following ACDF and posterior fusion, a significantly higher risk of complication was seen in the elderly compared with the nonelderly (reference group). The fusion level and comorbidity-adjusted ORs with $95 \%$ Cls for these groups were $1.54(1.40-1.68)$ and $1.25(1.06-1.46)$, respectively. In contrast, the elderly population had lower 30-day readmission rates in all 4 surgical cohorts (ACDF, 2.6\%; posterior fusion, 5.3\%; anterior/posterior fusion, $3.4 \%$; and laminoplasty, 3.6\%). The fusion level and comorbidity-adjusted odds ratios for 30-day readmissions for ACDF, posterior fusion, combined anterior and posterior fusion, and laminoplasty were $0.54(0.44-0.68), 0.32(0.24-0.44), 0.17$ $(0.08-0.38)$, and $0.39(0.18-0.85)$, respectively.

CONCLUSIONS The authors' analysis of the MarketScan database suggests a higher complication rate in the surgical treatment of CSM than previous national estimates. They found that elderly age ( $\geq 65$ years) significantly increased complication risk following ACDF and posterior fusion. Elderly patients were less likely to experience a readmission within 30 days of surgery. Postoperative complication occurrence, and 30-day readmission were significant drivers of total cost within 90 days of the index surgical procedure.

http://thejns.org/doi/abs/10.3171/2016.3.FOCUS1669

KEY WORDS adverse events; costs; cervical spondylotic myelopathy; MarketScan

$\mathrm{C}$ ERVICAL spondylotic myelopathy (CSM) is a degenerative cervical spine disease and the most frequent cause of spinal cord dysfunction in adults older than 55 years. ${ }^{15}$ Symptoms of CSM are often progressive and include neck or shoulder pain, paresthesias in the arms, inhibited fine motor control, and gait deficits. ${ }^{7}$ CSM results from age-related changes in the cervical spine, including degeneration of the vertebral bodies, intervertebral discs, and facet joints, as well as ossification of the posterior longitudinal ligament (OPLL). ${ }^{2,9}$ A 2013 systematic review found evidence to suggest that neurological deterioration will continue to occur in 20\%-62\% of patients if the natural course of CSM is uncorrected by surgical intervention. ${ }^{11}$

A surgical intervention can halt neurological deterioration associated with CSM in addition to improving the patient's functional status. ${ }^{1,4,6,10,13,14}$ A prospective study of 204 patients by Al-Tamimi et al. found that up to $70 \%$ of

ABBREVIATIONS ACDF = anterior cervical discectomy and fusion; COPD = chronic obstructive pulmonary disease; $\mathrm{CPT}=\mathrm{Current}$ Procedural Terminology; CSM = cervical spondylotic myelopathy; DVT = deep vein thrombosis; NIS = Nationwide Inpatient Sample; OPLL = ossification of the posterior longitudinal ligament. SUBMITTED February 2, 2016. ACCEPTED March 23, 2016.

INCLUDE WHEN CITING DOI: 10.3171/2016.3.FOCUS1669.

* Dr. Veeravagu and Mr. Connolly contributed equally to this work. 
patients with CSM treated surgically can expect objective quality of life improvements. ${ }^{1}$

While surgery for CSM is generally considered to be effective, complications occur and may impact patient outcomes. A recent multicenter prospective study of 479 CSM patients found a complication rate of $16.25 \%$ after surgical treatment; the most common occurrences were dysphagia, dural tear, and infection. The presence of OPLL was found to be a significant risk factor for complication occurrence, along with the comorbidity burden and operative duration. ${ }^{18}$ A 2016 systematic review found evidence that older patients, a longer operative duration, and a 2-stage surgery were important risk factors of perioperative complications following surgery for CSM. ${ }^{17}$

We used the MarketScan national longitudinal claims database to examine national trends, costs, and outcomes associated with different surgical treatments of CSM, including $\mathrm{ACDF}$, posterior fusion, combined anterior/ posterior fusion, and laminoplasty. The benefit of using a longitudinal national database includes a more comprehensive analysis of the complications, as well as costs associated with treating the CSM patient population in the United States. A 2015 study by Kaye et al. used the Nationwide Inpatient Sample (NIS) database from 2001 to 2010 to review the patient and surgical parameters associated with morbidity and mortality in CSM patients, finding a national morbidity rate of $9.83 \%$ and a mortality rate of $0.43 \% .^{5}$ This database study was unable to capture complications occurring after patient discharge and likely underestimates complication occurrence. In this study, we investigate more recent national outcomes from 2006 to 2010 and use a different database that has the advantage of longitudinal analysis including both inpatient and outpatient results.

\section{Methods \\ Data Source}

There has been a gradual increase over time in the number of comorbidities for patients opting to undergo surgical correction of CSM. ${ }^{12}$ Thus, a thorough analysis of trends related to these conditions was warranted. We performed a retrospective analysis of the complications and costs of surgical treatments for CSM on a national level. We examined outcomes at the index admission and within 30 days after surgery using the Thomson Reuters MarketScan Commercial Claims and Encounters and Medicare Supplemental databases, administered by Truven Health Analytics. The MarketScan database comprises data that include inpatient admission records, outpatient services, and pharmacy records from more than 100 payers in the United States.

\section{Cohort Definition}

MarketScan data for the years 2006 to 2010 were accessed using SAS software (version 9.3, SAS Institute, Inc.). Patients were selected using the criteria of a cervical spondylosis with myelopathy diagnosis (ICD-9 codes 721.1 and 722.71). Our general exclusion criteria included patients with any history of cancer, lymphoma, or leukemia (ICD-9 codes 140.x-172.x, 174.x-195.8, 200. x-208.x, and 196.x-199.1), and any vertebral fracture (ICD-9 805.00-806.09).

Procedure groups were identified using Current Procedural Terminology (CPT) coding; they include ACDF at C-2 or below (22551 or 22554), posterior fusion at C-2 or below (22600), combined anterior and posterior fusion at C-2 or below (22551 and 22600 or 22554 and 22600), and decompression of the spinal canal including laminoplasty (63050 or 63051). Multiple-level fusions were identified using the appropriate ICD-9 codes for 2-3 levels (81.62) and $4-8$ levels (81.63).

Cohort-specific exclusion criteria were the following (please see Table 1 for specific codes): The ACDF cohort excluded posterior cervical or any lumbar fusion, the posterior fusion cohort excluded anterior cervical, corpectomy, or any lumbar fusion, the combined cohort excluded lumbar fusion, and the laminoplasty cohort excluded any fusion, fusion devices, or corpectomy.

We identified 35,962 patients overall (Fig. 1). Patient characteristics of age, sex, comorbidities, geographic region, and insurance plan type were identified from the database. The patient comorbidity burden was determined from outpatient records prior to admission with appropriate ICD-9 diagnosis codes (Table 1).

\section{Analyzed Outcomes}

We determined comorbidities and outcomes using the inpatient and outpatient records of MarketScan. To capture complications, we partitioned inpatient and outpatient records into those occurring before and after the index surgical procedure admission date. We then collected complications using the codes listed in Table 1 occurring before, during, and within 30 days after the index surgical discharge date. A complication was considered new if the patient had no prior history of the complication type in previous records. Comorbid conditions were collected using ICD-9 diagnosis codes (Table 1).

Hospital payments (total hospital payments for covered services during an admission), physician payments (total physician payments for covered services rendered by the principal physician), and total payments (total payments from all providers) were collected from the index inpatient admission records. To capture all potential long-term expenses of adverse events, we also calculated the total costs accumulated within 90 days after discharge from the index surgical admission. The 90-day associated costs were calculated using the sum of outpatient charges and total payments (as defined above) from the inpatient records. Costs associated with the index admission were not included.

\section{Statistical Analysis}

Data were prepared and analyzed using SAS software (version 9.3, SAS Institute, Inc.) and R (version 3.2.3). Logistic regression was used to calculate odds ratios (elderly vs nonelderly patients) adjusted for fusion level and comorbidities. The associated $p$ values were based on a Wald chi-square test. To evaluate drivers of payments of all costs (total payments from index admission plus 90-day postoperative costs) associated with complications that occurred 
TABLE 1. Codes used to define procedures, comorbidities, and complications

\begin{tabular}{|c|c|}
\hline $\begin{array}{l}\text { Comorbidities \& Complications } \\
\text { (coding system) }\end{array}$ & Code \\
\hline Tobacco use (ICD-9) & $305.1, V 15.82,989.84,649.0$ \\
\hline Osteoporosis (ICD-9) & 733, V17.81, 731.3, V82.81 \\
\hline $\begin{array}{l}\text { Wound complication (CPT, } \\
\text { ICD-9) }\end{array}$ & $\begin{array}{c}10060,10140,10180,12020,12021 \\
20005,21501,22010,22015 \\
998.0,998.5,999.3,998.3,998.1 \\
998.3,998.81,998.83,998.4\end{array}$ \\
\hline $\begin{array}{l}\text { General neurological compli- } \\
\text { cation (ICD-9) }\end{array}$ & $\begin{array}{l}430,431,432,433,434,435,436 \\
\quad 438.2,438.3,438.4,438.5\end{array}$ \\
\hline $\begin{array}{l}\text { Pulmonary complication } \\
\text { (ICD-9) }\end{array}$ & $\begin{array}{l}997.3,518.4,518.5,518.7,518.81 \\
518.82,518.83,518.84,518.89 \\
519.1\end{array}$ \\
\hline Cardiac complication (ICD-9) & $\begin{array}{c}\text { 410, 412, 998.0, 997.1, 411, 429.7 } \\
\text { 427, 426.1, 426, 426.3, 426.4 } \\
426.5,426.6,426.7,426.8\end{array}$ \\
\hline Pulmonary embolism (ICD-9) & 415.1 \\
\hline Thromboemboli (ICD-9) & $453.0,453.4,453.8,453.2,453.3$ \\
\hline Deep vein thrombosis (ICD-9) & $\begin{array}{l}451,453.4,453.8,453.2,453.1 \\
\quad 453.9\end{array}$ \\
\hline Delerium (ICD-9) & 293 \\
\hline Dysphagia (ICD-9) & 787.2 \\
\hline CSM (ICD-9) & $721.1,722.71$ \\
\hline ACDF (CPT) & 22551,22554 \\
\hline Posterior fusion (CPT) & 22600 \\
\hline Laminectomy (CPT) & 63050,63051 \\
\hline $\begin{array}{l}\text { Any lumbar fusion/refusion } \\
\text { (CPT) }\end{array}$ & $\begin{array}{l}22558,22857,22862,22865,22586, \\
\quad 22612,22630,22633\end{array}$ \\
\hline Corpectomy (CPT) & $\begin{array}{l}22554,63081,63300,63304,63085 \\
\quad 63101,63301,63305,63087 \\
63090,63102,63302,63303 \\
63306,63007\end{array}$ \\
\hline Fusion devices (CPT) & $\begin{array}{l}22845,22846,22847,22851,63290 \\
\text { 22840, } 22848,22849,22841 \\
22842,22843,22844\end{array}$ \\
\hline 2- to 3-level fusion (ICD-9) & 81.62 \\
\hline 4- to 8-level fusion (ICD-9) & 81.63 \\
\hline
\end{tabular}

during and after the index procedure, we performed an ordinary least squares regression. Feature pairs with a correlation greater than 0.75 were removed.

\section{Results}

\section{Patient Characteristics}

The characteristics of our 35,962 CSM patients are summarized in Table 2. Our assessment of patient comorbidities began by dividing the overall patient cohort into 4 groups, based on the specific procedure performed. Surgical options included ACDF $(\mathrm{n}=30,600,85.1 \%)$, posterior fusion $(\mathrm{n}=3540,9.8 \%)$, combined anterior/posterior fu- sion $(\mathrm{n}=957,2.7 \%)$, and laminoplasty $(\mathrm{n}=865,2.4 \%)$. Approximately $88 \%$ of patients from each procedure cohort had a follow-up of at least 90 days. Overall, approximately 93\% of patients were discharged home. The majority of patients who were not discharged home were discharged to an inpatient rehabilitation facility (3\%) or a skilled nursing facility $(2 \%)$.

The comorbidity burden is summarized in Table 3 . For the ACDF cohort, certain trends in comorbid conditions were noted. The most common comorbidities included hypertension $(45.0 \%)$, uncomplicated diabetes $(17.8 \%)$, and chronic obstructive pulmonary disease (COPD) (17.4\%). Similar comorbidity trends were noted for the posterior fusion, combined anterior/posterior fusion, and laminoplasty cohorts. The combined anterior/posterior cohort had the highest incidence of osteoporosis (20.6\%).

\section{Outcomes}

A summary of the postoperative outcomes in each surgical cohort is shown in Table 4. Age-stratified outcomes are shown in Table 5 with odds ratios adjusted for fusion level and the 10 comorbidities listed in Table 3.

Overall, patients older than 65 years experienced increased rates of the occurrence of any complication for all procedure cohorts except the laminoplasty cohort and decreased rates of 30-day readmissions for all 4 procedure cohorts that we investigated.

\section{ACDF}

We found an overall complication rate of $15.6 \%$ in the CSM patients who underwent ACDF. Commonly occurring complications were wound complications (2.0\%), pulmonary complications $(2.5 \%)$, cardiac complications (4.2\%), and dysphagia (4.1\%)

Within this cohort, a significantly higher frequency of any complication occurrence was seen in the elderly population compared with the nonelderly counterparts (22.3\% vs $14.7 \%$, respectively, $\mathrm{p}<0.0001)$. However, the 30 -day readmission rate was significantly lower in the elderly group (2.6\% compared with $3.8 \%$ in the nonelderly group, $\mathrm{p}<0.0001)$. The elderly group had a significantly higher risk of experiencing any complication (adjusted OR 1.54) and a significantly lower risk of experiencing a 30-day readmission (adjusted OR 0.54).

\section{Posterior Fusion}

We found an overall complication rate of $29.2 \%$ in the CSM patients who underwent posterior fusion. Commonly occurring complications were cardiac complications (8.6\%), pulmonary complications (5.9\%), and wound complications $(5.9 \%)$. New chronic pain occurred in approximately $2.0 \%$ of patients. A significantly higher frequency of any complication occurrence was seen in the elderly population compared with the nonelderly group $(32.3 \%$ versus $27.9 \%$, respectively, $p=0.0084$ ). Interestingly, this group had the highest incidence of deep vein thrombosis (DVT) (2.6\%). The elderly group had a significantly higher risk of experiencing any complication (adjusted OR 1.25 ) and a significantly lower risk of experiencing a 30day readmission (adjusted OR 0.32). 

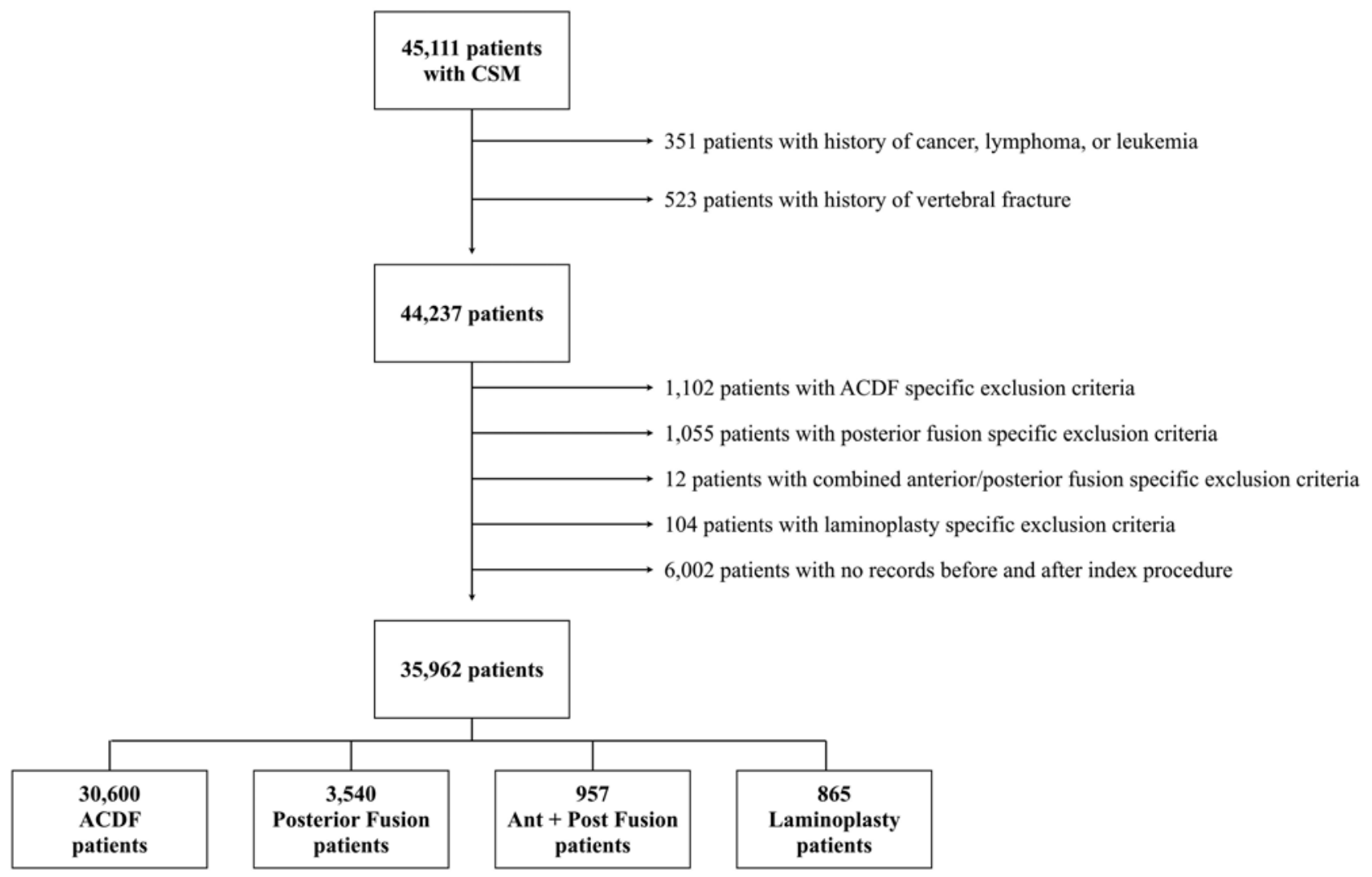

FIG. 1. Flowchart of cohort selection. Ant + Post = anterior and posterior.

\section{Combined Anterior and Posterior Fusion}

We found an overall complication rate of $41.1 \%$ (29.3\% excluding dysphagia) in the CSM patients who underwent combined anterior and posterior fusion. Notable complications for this group included dysphagia (11.3\%), cardiac complications $(8.6 \%)$, and pulmonary complications $(18.3 \%)$. The overall complication rate was approximately the same for elderly and nonelderly patients $(45.2 \%$ and $39.9 \%, \mathrm{p}=0.4306)$. The 30 -day readmission rate was significantly lower in the elderly group (3.4\% compared with $15.1 \%$ in the elderly group, $\mathrm{p}<0.0001$ ). The elderly group had a significantly lower risk of experiencing a 30-day readmission (adjusted OR 0.17, $\mathrm{p}<0.0001$ ).

\section{Laminoplasty Outcomes}

We found an overall complication rate of $22.4 \%$ in the CSM patients who underwent laminoplasty. Notable complications in this procedure group were cardiac complications (7.4\%), wound complications (5.3\%), and pulmonary complications (3.0\%). Interestingly, this procedure group had the lowest rate of dysphagia $(0.35 \%)$. Within this cohort, similar rates of any complication occurrence were seen in the elderly $(25.1 \%)$ compared with the nonelderly $(21.5 \%)$ populations $(\mathrm{p}=0.4511)$. The elderly group had a significantly lower risk of experiencing a 30-day readmission (adjusted OR 0.39, $\mathrm{p}=0.0180$ ).

\section{Costs}

We performed an ordinary least squares regression to identify the primary drivers of 90-day payments for the ACDF and posterior fusion (Table 6). Due to limited numbers in the combined anterior/posterior fusion cohort and the laminoplasty cohort, we chose not to conduct regression analysis on these groups. The base costs for ACDF and posterior fusion were $\$ 26,127$ and $\$ 26,811$, respectively. The largest drivers of cost within 90 days for ACDF were 30-day readmission $(\$ 28,658, \mathrm{p}<0.0001)$, pulmonary complications $(\$ 20,268, \mathrm{p}<0.0001)$, DVT $(\$ 18,943$, $\mathrm{p}<0.0001)$, and delirium $(\$ 17,404, \mathrm{p}<0.0001)$. Neurological complications and wound complications were also associated with increases of greater than $\$ 5000$ (both $p$ $<0.05)$. Patients who were discharged to a location other than home had an associated increase in cost of $\$ 6658$ ( $p$ $<0.0001)$.

Large drivers of cost in the posterior fusion cohort were the occurrence of 30-day readmission $(\$ 30,357, \mathrm{p}$ $<0.0001)$, dysphagia $(\$ 30,052, \mathrm{p}<0.0001)$, neurological complications $(\$ 25,788, \mathrm{p}<0.0001)$, and pulmonary embolism $(\$ 24,524, \mathrm{p}=0.0084)$.

\section{Discussion}

CSM is a potentially debilitating disease with multiple treatment options. In recent years, surgical treatment options have been increasingly used..$^{12}$ Multiple studies have sought to assess trends related to these procedures. .,12,16 $^{2}$ Lad et al. used the NIS database between 1993 and 2002 to assess the national trends in spinal fusion for CSM and found that while the number of comorbidities in patients 
TABLE 2. Patient demographics stratified by ACDF, posterior fusion, combined anterior/posterior fusion, and laminoplasty cohorts

\begin{tabular}{|c|c|c|c|c|}
\hline Variable & $\operatorname{ACDF}(n=30,600)$ & Posterior $(n=3540)$ & Ant+Post ( $n=957)$ & Laminoplasty $(n=865)$ \\
\hline Mean age in yrs (SD) & $53.13(10.62)$ & $60.34(11.39)$ & $58.34(10.01)$ & $58.53(10.93)$ \\
\hline Mean length of stay (SD) & $1.81(2.33)$ & $4.25(4.2)$ & $4.95(4.68)$ & $3.03(2.19)$ \\
\hline Male, $\mathrm{n}(\%)$ & $14,887(48.65)$ & $2063(58.28)$ & $496(51.83)$ & $580(67.05)$ \\
\hline Discharged home, n (\%) & $27,960(91.37)$ & $2710(76.55)$ & $731(76.38)$ & $740(85.55)$ \\
\hline Medicare, $\mathrm{n}(\%)$ & $3804(12.43)$ & 1109 (31.33) & $216(22.57)$ & $222(25.66)$ \\
\hline \multicolumn{5}{|l|}{ Region, n (\%) } \\
\hline Northeast & $3597(11.75)$ & $617(17.43)$ & $157(16.41)$ & $132(15.26)$ \\
\hline North Central & $6455(21.09)$ & $962(27.18)$ & $183(19.12)$ & $241(27.86)$ \\
\hline South & $15,753(51.48)$ & $1415(39.97)$ & $444(46.39)$ & $300(34.68)$ \\
\hline West & $4215(13.77)$ & $475(13.42)$ & $157(16.41)$ & $170(19.65)$ \\
\hline Unknown & $580(1.9)$ & $71(2.01)$ & $16(1.67)$ & $22(2.54)$ \\
\hline \multicolumn{5}{|l|}{ Insurance plan type, n (\%) } \\
\hline Comprehensive & $2422(7.92)$ & $585(16.53)$ & $111(11.6)$ & $102(11.79)$ \\
\hline EPO & $264(0.86)$ & $23(0.65)$ & $4(0.42)$ & $10(1.16)$ \\
\hline HMO & $3566(11.65)$ & $397(11.21)$ & $95(9.93)$ & $107(12.37)$ \\
\hline POS & $2338(7.64)$ & $243(6.86)$ & $71(7.42)$ & $66(7.63)$ \\
\hline PPO & $19,101(62.42)$ & $1968(55.59)$ & $577(60.29)$ & $511(59.08)$ \\
\hline POS w/ capitation & $211(0.69)$ & $27(0.76)$ & $7(0.73)$ & $3(0.35)$ \\
\hline CDHP & $695(2.27)$ & $53(1.5)$ & $25(2.61)$ & $21(2.43)$ \\
\hline HDHP & $201(0.66)$ & $29(0.82)$ & $6(0.63)$ & $9(1.04)$ \\
\hline Unknown & $1802(5.89)$ & $215(6.07)$ & $61(6.37)$ & $36(4.16)$ \\
\hline
\end{tabular}

Ant+post = combined anterior/posterior fusion; $\mathrm{CDHP}=$ consumer-driven health plan; $\mathrm{EPO}=$ exclusive provider organization; $\mathrm{HDHP}=$ hospitaldriven health plan; $\mathrm{HMO}=$ health maintenance organization; $\mathrm{POS}=$ point of service; $\mathrm{PPO}=$ preferred provider organization.

opting to undergo surgical treatment has steadily increased, the overall complication and mortality rates have remained relatively stable at $10.3 \% .{ }^{12}$ However, use of the NIS database may not adequately capture complications occurring after patient discharge, thereby underestimating complication occurrence. We therefore conducted a retrospective analysis of CSM patients undergoing surgical treatment using MarketScan, a longitudinal national database.

\section{Analysis of Complications}

We found an overall complication rate of $15.6 \%$ after ACDF, $29.2 \%$ after posterior fusion, $41.1 \%$ after combined anterior and posterior fusion, and $22.4 \%$ after laminoplasty. Our rates of adverse events were consistently higher than those reported in previous national cohort studies using the NIS database, likely because of our advantage in tracking patients after discharge. According to the NIS, CSM patients who underwent spinal fusion surgery be-

TABLE 3. Patient comorbidities stratified by ACDF, posterior fusion, combined anterior/posterior fusion, and laminoplasty cohorts

\begin{tabular}{lcccc}
\hline & \multicolumn{4}{c}{ No. of Patients $(\%)$} \\
\cline { 2 - 5 } Comorbidities (comorbidity index) & ACDF $(\mathrm{n}=30,600)$ & Posterior $(\mathrm{n}=3540)$ & Ant+Post $(\mathrm{n}=957)$ & Laminoplasty $(\mathrm{n}=865)$ \\
\hline Tobacco & $2759(9.02)$ & $280(7.91)$ & $82(8.57)$ & $65(7.51)$ \\
\hline Osteoporosis & $3997(13.06)$ & $628(17.74)$ & $197(20.59)$ & $100(11.56)$ \\
\hline Hypertension (Elixhauser) & $13,779(45.03)$ & $2028(57.29)$ & $538(56.22)$ & $455(52.6)$ \\
\hline CHF (Charlson) & $934(3.05)$ & $188(5.31)$ & $37(3.87)$ & $38(4.39)$ \\
\hline COPD (Charlson) & $5317(17.38)$ & $691(19.52)$ & $187(19.54)$ & $145(16.76)$ \\
\hline Myocardial infarction (Charlson) & $851(2.78)$ & $153(4.32)$ & $30(3.13)$ & $27(3.12)$ \\
\hline Uncomplicated diabetes (Charlson) & $5446(17.8)$ & $822(23.22)$ & $186(19.44)$ & $192(22.2)$ \\
\hline Complicated diabetes (Charlson) & $1204(3.93)$ & $250(7.06)$ & $56(5.85)$ & $51(5.9)$ \\
\hline Obesity (Elixhauser) & $1625(5.31)$ & $147(4.15)$ & $44(4.6)$ & $44(5.09)$ \\
\hline Drug abuse (Elixhauser) & $379(1.24)$ & $36(1.02)$ & $11(1.15)$ & $5(0.58)$ \\
\hline
\end{tabular}

$\mathrm{CHF}=$ congestive heart failure. 
TABLE 4. Postoperative complications in ACDF, posterior fusion, combined anterior/posterior fusion, and laminoplasty cohorts

\begin{tabular}{|c|c|c|c|c|}
\hline \multirow[b]{2}{*}{ Variable } & \multicolumn{4}{|c|}{ No. of Patients (\%) } \\
\hline & $\begin{array}{c}\text { ACDF } \\
(n=30,600)\end{array}$ & $\begin{array}{l}\text { Posterior } \\
(n=3540)\end{array}$ & $\begin{array}{l}\text { Ant+Post } \\
(n=957)\end{array}$ & $\begin{array}{l}\text { Laminoplasty } \\
\qquad(\mathrm{n}=865)\end{array}$ \\
\hline $\begin{array}{l}\text { Wound } \\
\text { compli- } \\
\text { cation }\end{array}$ & $606(1.98)$ & $210(5.93)$ & $60(6.27)$ & $46(5.32)$ \\
\hline Delirium & $78(0.25)$ & $45(1.27)$ & $13(1.36)$ & $7(0.81)$ \\
\hline $\begin{array}{c}\text { Chronic } \\
\text { pain }\end{array}$ & $336(1.1)$ & $71(2.01)$ & $18(1.88)$ & $10(1.16)$ \\
\hline $\begin{array}{c}\text { Pulmonary } \\
\text { embo- } \\
\text { lism }\end{array}$ & $78(0.25)$ & $28(0.79)$ & $7(0.73)$ & $8(0.92)$ \\
\hline DVT & $214(0.7)$ & $93(2.63)$ & $13(1.36)$ & $12(1.39)$ \\
\hline $\begin{array}{c}\text { Thrombo- } \\
\text { embo- } \\
\text { lism }\end{array}$ & $144(0.47)$ & $49(1.38)$ & $9(0.94)$ & $7(0.81)$ \\
\hline $\begin{array}{c}\text { Pulmonary } \\
\text { compli- } \\
\text { cation }\end{array}$ & $768(2.51)$ & $207(5.85)$ & $175(18.29)$ & $26(3.01)$ \\
\hline $\begin{array}{c}\text { General } \\
\text { neuro- } \\
\text { logical } \\
\text { compli- } \\
\text { cation }\end{array}$ & $324(1.06)$ & $76(2.15)$ & $17(1.78)$ & $18(2.08)$ \\
\hline $\begin{array}{l}\text { Cardiac } \\
\text { compli- } \\
\text { cation }\end{array}$ & $1282(4.19)$ & $304(8.59)$ & $82(8.57)$ & $64(7.4)$ \\
\hline Dysphagia & $1264(4.13)$ & $55(1.55)$ & $108(11.29)$ & $3(0.35)$ \\
\hline $\begin{array}{l}\text { Any compli- } \\
\text { cation }\end{array}$ & $4765(15.57)$ & $1034(29.21)$ & $393(41.07)$ & $194(22.43)$ \\
\hline $\begin{array}{l}\text { Any com- } \\
\text { plication } \\
\text { excluding } \\
\text { dyspha- } \\
\text { gia }\end{array}$ & $2724(8.9)$ & $727(20.54)$ & $280(29.26)$ & $142(16.42)$ \\
\hline $\begin{array}{l}\text { 30-day } \\
\text { readmis- } \\
\text { sion }\end{array}$ & $1119(3.66)$ & $421(11.89)$ & $120(12.54)$ & $62(7.17)$ \\
\hline Mortality & $25(0.08)$ & $8(0.23)$ & $5(0.52)$ & - \\
\hline
\end{tabular}

DVT = deep vein thrombosis.

tween 1993 and 2002 had an overall complication rate of $13.4 \%$ and a mortality rate of $0.6 \% .^{3}$ A more recent NIS study assessing anterior and/or posterior cervical fusion or laminoplasty between 2001 and 2010 found a total complication rate of $9.83 \%$ and a mortality rate of $0.43 \% .^{5}$

Despite our higher complication rate findings, our mortality rates were largely comparable to those of NIS studies. This is likely because the MarketScan database does not adequately capture mortality after discharge since, similar to the NIS, it is only found in inpatient records. Our complication rates were more similar to a prospective, multicenter study conducted in 2012 of 302 patients, which found an overall complication rate of $15.6 \%$. In particular, their anterior-only, posterior-only, and combined anterior/ posterior procedures had complication rates of $11 \%, 19 \%$, and $37 \%$, respectively, which was a trend that we similarly found in our own ACDF, posterior fusion, and combined anterior/posterior fusion cohorts. ${ }^{8}$

We stratified our patient cohort by age to compare complication occurrence. Age had the strongest impact on complications following ACDF and posterior fusion. Limited patient numbers in our combined anterior/posterior fusion and laminectomy cohorts may have influenced our ability to detect differences in complication occurrences for elderly and nonelderly patients in these cohorts.

Our results validated prior findings of the impact of increased age on higher complication risks, while providing the distinct advantage of utilizing a longitudinal national claims database with extended follow-up. In a previous study, we demonstrated that an increasing number of postoperative complications can be captured in longitudinal administrative databases compared with nonlongitudinal databases as early as 30 days after the index surgical procedure. ${ }^{19}$ Boakye et al. examined NIS data for spinal fusion surgery from 1993 to 2002 and similarly discovered that age had an impact on the development of complications in the CSM population. In particular, the authors found that patients between 65 and 84 years old were 8 times more likely to have a postoperative adverse event, while patients 85 years and older were 45 times more likely to have a complication. ${ }^{3}$ Fehlings et al. used a prospective cohort from multiple institutions and found that age was a significant predictor of major complication occurrence. ${ }^{8}$

\section{Cost Analysis}

A 2008 review of the NIS database for the surgical correction of CSM through spinal fusion found that the presence of one postoperative adverse event increased hospital charges by more than $\$ 15,000 .{ }^{3}$ Our study expands on the NIS findings of costs associated with CSM surgical treatments by showing the incremental costs associated with complications for ACDF and posterior fusion procedures in CSM patients. Complication cost estimates are likely larger than those reported in the previous study because this study included admission costs with 90-day payments after discharge. The longitudinal nature of MarketScan may also be a driver of increased cost estimates when compared with NIS. Nonetheless, our study shows that the financial burden of adverse events associated with surgery for CSM may extend beyond the surgical admission. Minimizing the occurrence of complications in the perioperative period plays an important role in reducing health care costs.

\section{Limitations}

There are several limitations inherent to studies that use administrative databases. First, analysis is limited to the data available within the MarketScan database. Thus, it is not possible to investigate demographic characteristics such as patient ethnicity and other important clinical variables such as degree of cervical compression or anatomical level operated upon. It is also likely that mortality was not adequately captured, as this is only recorded in the MarketScan inpatient record. Any deaths occurring 
TABLE 5. Overall postoperative outcomes stratified by age*

\begin{tabular}{|c|c|c|c|c|}
\hline Procedure & Elderly ( $\geq 65$ yrs) $(n=5154)$ & Nonelderly $(n=30,808)$ & OR $(95 \% \mathrm{Cl})$ & p Value \\
\hline \multicolumn{5}{|l|}{ ACDF } \\
\hline Any complication & $814(22.26)$ & $3951(14.66)$ & $1.54(1.4-1.68)$ & $<0.0001$ \\
\hline 30-day readmission & $94(2.57)$ & $1025(3.8)$ & $0.54(0.44-0.68)$ & $<0.0001$ \\
\hline \multicolumn{5}{|l|}{ Posterior } \\
\hline Any complication & $346(32.34)$ & $688(27.85)$ & $1.25(1.06-1.46)$ & 0.0084 \\
\hline 30-day readmission & $57(5.33)$ & $364(14.74)$ & $0.32(0.24-0.44)$ & $<0.0001$ \\
\hline \multicolumn{5}{|l|}{ Ant+post } \\
\hline Any complication & $94(45.19)$ & 299 (39.92) & $1.14(0.82-1.59)$ & 0.4306 \\
\hline 30-day readmission & $7(3.37)$ & $113(15.09)$ & $0.17(0.08-0.38)$ & $<0.0001$ \\
\hline \multicolumn{5}{|l|}{ Laminoplasty } \\
\hline Any complication & $55(25.11)$ & $139(21.52)$ & $1.15(0.8-1.68)$ & 0.4511 \\
\hline 30-day readmission & $8(3.65)$ & $54(8.36)$ & $0.39(0.18-0.85)$ & 0.0180 \\
\hline
\end{tabular}

* Adjusted for fusion level, tobacco use, osteoporosis, hypertension, congestive heart failure, COPD, myocardial infarction, uncomplicated diabetes, complicated diabetes, obesity, and drug abuse.

in a nonhospital setting are not available in the database. Second, because MarketScan is primarily a database composed of privately insured patients, this study population is not an accurate representation of the true heterogeneous patient population. Lastly, because the study is limited to 4 years of MarketScan data, a query to investigate the effects of infrequent comorbid conditions such as OPLL was not possible due to limited patient numbers. Similarly our patient numbers for our combined anterior/posterior fusion group and our laminoplasty group suffered from low numbers, which may have influenced our ability to detect differences in outcome among elderly and nonelderly patients in these groups. We were also not able to investigate the effect of age on health care costs since all elderly patients in the cohort were covered through Medicare, which may influence payment amount.

\section{Conclusions}

Our analysis of the MarketScan database suggests a higher complication rate in the surgical treatment of CSM than previously found in national estimates. We found that elderly age significantly increased complication risk following $\mathrm{ACDF}$ and posterior fusion. In all procedure groups, elderly patients were less likely to experience a readmission within 30 days of the index surgery. Our analysis of the data also suggested the primary driver of cost to be the occurrence of at least one postoperative outcome after surgery.

\section{References}

1. Al-Tamimi YZ, Guilfoyle M, Seeley H, Laing RJ: Measure-

TABLE 6. Ordinary least squares regression of drivers of cost in US dollars adjusted for fusion level, elderly age status, tobacco use, osteoporosis, hypertension, CHF, COPD, MI, diabetes uncomplicated, diabetes complicated, obesity, and drug abuse

\begin{tabular}{|c|c|c|c|c|}
\hline \multirow[b]{2}{*}{ Variable } & \multicolumn{2}{|c|}{ ACDF } & \multicolumn{2}{|c|}{ Posterior Fusion } \\
\hline & $\begin{array}{c}\text { Beta Coefficient } \\
\text { (incremental cost) }\end{array}$ & $p$ Value & $\begin{array}{c}\text { Beta Coefficient } \\
\text { (incremental cost) }\end{array}$ & $\mathrm{p}$ Value \\
\hline (Intercept) & $\$ 26,127$ & $<0.0001$ & $\$ 26,811$ & $<0.0001$ \\
\hline Cardiac complication & $\$ 6040$ & $<0.0001$ & $\$ 5135$ & 0.0847 \\
\hline Wound complication & $\$ 7974$ & $<0.0001$ & $\$ 3105$ & 0.3898 \\
\hline 30-day readmission & $\$ 28,658$ & $<0.0001$ & $\$ 30,357$ & $<0.0001$ \\
\hline Not discharged home & $\$ 6658$ & $<0.0001$ & $\$ 12,545$ & $<0.0001$ \\
\hline General neurological complication & $\$ 10,065$ & $<0.0001$ & $\$ 25,788$ & $<0.0001$ \\
\hline Delirium & $\$ 17,404$ & $<0.0001$ & $\$ 19,116$ & 0.0083 \\
\hline Chronic pain & $\$ 2678$ & 0.0618 & $\$ 646$ & 0.9116 \\
\hline Pulmonary embolism & $-\$ 5320$ & 0.0860 & $\$ 24,524$ & 0.0084 \\
\hline DVT & $\$ 18,943$ & $<0.0001$ & $\$ 13,615$ & 0.0089 \\
\hline Pulmonary complication & $\$ 20,268$ & $<0.0001$ & $\$ 21,755$ & $<0.0001$ \\
\hline Dysphagia & $\$ 3694$ & $<0.0001$ & $\$ 30,052$ & $<0.0001$ \\
\hline
\end{tabular}


ment of long-term outcome in patients with cervical spondylotic myelopathy treated surgically. Eur Spine J 22:25522557, 2013

2. Baptiste DC, Fehlings MG: Pathophysiology of cervical myelopathy. Spine J 6 (6 Suppl):190S-197S, 2006

3. Boakye M, Patil CG, Santarelli J, Ho C, Tian W, Lad SP: Cervical spondylotic myelopathy: complications and outcomes after spinal fusion. Neurosurgery 62:455-461, 2008

4. Cheung WY, Arvinte D, Wong YW, Luk KD, Cheung KM: Neurological recovery after surgical decompression in patients with cervical spondylotic myelopathy-a prospective study. Int Orthop 32:273-278, 2008

5. David Kaye I, Marascalchi BJ, Macagno AE, Lafage VA, Bendo JA, Passias PG: Predictors of morbidity and mortality among patients with cervical spondylotic myelopathy treated surgically. Eur Spine J 24:2910-2917, 2015

6. Demura S, Murakami H, Kawahara N, Kato S, Yoshioka K, Tsuchiya H: Laminoplasty and pedicle screw fixation for cervical myelopathy associated with athetoid cerebral palsy: minimum 5-year follow-up. Spine (Phila Pa 1976) 38:17641769,2013

7. Emery SE: Cervical spondylotic myelopathy: diagnosis and treatment. J Am Acad Orthop Surg 9:376-388, 2001

8. Fehlings MG, Smith JS, Kopjar B, Arnold PM, Yoon ST, Vaccaro AR, et al: Perioperative and delayed complications associated with the surgical treatment of cervical spondylotic myelopathy based on 302 patients from the AOSpine North America Cervical Spondylotic Myelopathy Study. J Neurosurg Spine 16:425-432, 2012

9. Fehlings MG, Tetreault LA, Wilson JR, Skelly AC: Cervical spondylotic myelopathy: current state of the art and future directions. Spine (Phila Pa 1976) 38 (22 Suppl 1): S1-S8, 2013

10. Fehlings MG, Wilson JR, Kopjar B, Yoon ST, Arnold PM, Massicotte EM, et al: Efficacy and safety of surgical decompression in patients with cervical spondylotic myelopathy: results of the AOSpine North America prospective multicenter study. J Bone Joint Surg Am 95:1651-1658, 2013

11. Karadimas SK, Erwin WM, Ely CG, Dettori JR, Fehlings MG: Pathophysiology and natural history of cervical spondylotic myelopathy. Spine(Phila Pa 1976) 38 (22 Suppl 1):S21-S36, 2013

12. Lad SP, Patil CG, Berta S, Santarelli JG, Ho C, Boakye M: National trends in spinal fusion for cervical spondylotic myelopathy. Surg Neurol 71:66-69, 2009

13. Machino M, Yukawa Y, Hida T, Ito K, Nakashima H, Kanbara S, et al: Modified double-door laminoplasty in managing multilevel cervical spondylotic myelopathy: surgical outcome in 520 patients and technique description. J Spinal Disord Tech 26:135-140, 2013
14. Machino M, Yukawa Y, Imagama S, Ito K, Katayama Y, Matsumoto T, et al: Surgical treatment assessment of cervical laminoplasty using quantitative performance evaluation in elderly patients: a prospective comparative study in 505 patients with cervical spondylotic myelopathy. Spine (Phila Pa 1976) [epub ahead of print], 2015

15. McCormick WE, Steinmetz MP, Benzel EC: Cervical spondylotic myelopathy: make the difficult diagnosis, then refer for surgery. Cleve Clin J Med 70:899-904, 2003

16. Ney JP, van der Goes DN, Nuwer MR: Does intraoperative neurophysiologic monitoring matter in noncomplex spine surgeries? Neurology 85:2151-2158, 2015

17. Tetreault L, Ibrahim A, Côté P, Singh A, Fehlings MG: A systematic review of clinical and surgical predictors of complications following surgery for degenerative cervical myelopathy. J Neurosurg Spine 24:77-99, 2016

18. Tetreault L, Tan G, Kopjar B, Côté P, Arnold P, Nugaeva N, et al: Clinical and surgical predictors of complications following surgery for the treatment of cervical spondylotic myelopathy: results from the multicenter, prospective AOSpine international study of 479 patients. Neurosurgery [epub ahead of print], 2015

19. Veeravagu A, Cole TS, Azad TD, Ratliff JK: Improved capture of adverse events after spinal surgery procedures with a longitudinal administrative database. J Neurosurg Spine 23:374-382, 2015

\section{Disclosures}

The authors report no conflict of interest concerning the materials or methods used in this study or the findings specified in this paper.

\section{Author Contributions}

Conception and design: Ratliff, Veeravagu, Connolly, Lamsam, Azad, Desai. Acquisition of data: Connolly, Lamsam. Analysis and interpretation of data: Ratliff, Veeravagu, Connolly, Lamsam, Desai. Drafting the article: Veeravagu, Connolly, Li, Swinney. Critically revising the article: Ratliff, Veeravagu, Connolly, Li. Reviewed submitted version of manuscript: Veeravagu, Connolly. Statistical analysis: Connolly, Lamsam.

\section{Correspondence}

John Ratliff, Department of Neurosurgery, Stanford University Medical Center, 300 Pasteur Dr., R291 MC 5327, Stanford, CA 94305-5327. email: jratliff@stanford.edu. 